Institute of $\mathbf{F}_{\text {ood and }} \mathbf{A}_{\text {gricultural }} \mathbf{S}_{\text {ciences }}$

\title{
Wasp Parasitoid Meteorus autographae Muesebeck (Insecta: Hymenoptera: Braconidae) ${ }^{1}$
}

Andrei Sourakov and Everett Mitchell ${ }^{2}$

\section{Distribution}

Meteorus autographae is found in Newfoundland south to Florida, and then west to Wisconsin and Louisiana.

\section{Description}

\section{Egg}

The egg is clear and thin-walled. Soon after oviposition, the folded-in-two larva can be observed inside.

\section{Larva}

The larva is translucent, long and slender, with a pronounced sclerotized head. Often more than one egg is laid, but the first larva to emerge kills its siblings.

\section{Pupa}

The brown-colored, $5 \mathrm{~mm}$-long cocoon usually is suspended from the edge of the leaf on a silk string.

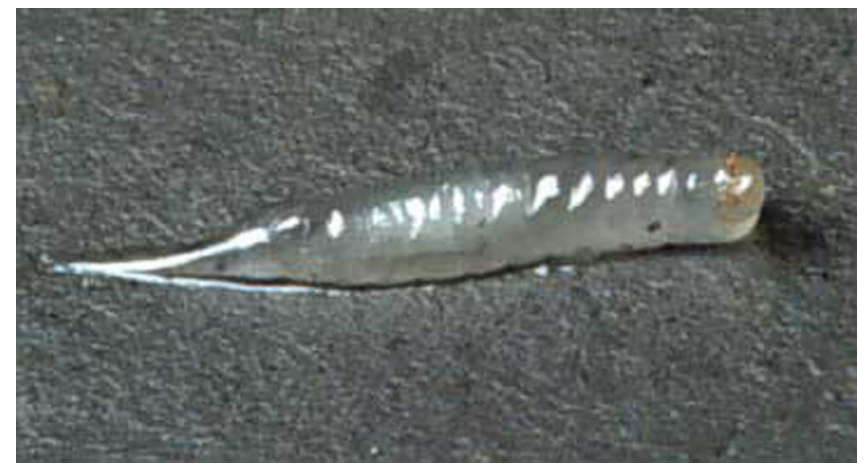

Figure 1. Mature larva of Meteorus autographae Muesebeck, a parasitoid wasp. Credits: Andrei Sourakov, USDA

\section{Adult}

The adult wasp is orange, with black eyes and antennae. The body does not exceed $6 \mathrm{~mm}$. The female has a well-defined black ovipositor.

\section{Life History}

This parasitoid attacks most instars of noctuid larvae in Florida.. It develops from egg to pupa in eight days at 27 degrees $C$. Six days later, the adult hatches and lives on average 40 days. Wasps also develop and survive better at cooler temperatures.

1. This document is EENY-125, one of a series of Featured Creatures from the Entomology and Nematology Department, Florida Cooperative Extension Service, Institute of Food and Agricultural Sciences, University of Florida. Published: March 2000. Revised: October 2002. This document is also available on Featured Creatures Website at http://creatures.ifas.ufl.edu. Please visit the EDIS Website at http://edis.ifas.ufl.edu. Additional information on these organisms, including many color photographs, is available at the Entomology and Nematology Department website at http://entnemdept.ifas.ufl.edu/. 2. Andrei Sourakov and Everett Mitchell, USDA, Gainesville, FL.

The Institute of Food and Agricultural Sciences is an equal opportunity/affirmative action employer authorized to provide research, educational information and other services only to individuals and institutions that function without regard to race, color, sex, age, handicap, or national origin. For information on obtaining other extension publications, contact your county Cooperative Extension Service office. Florida Cooperative Extension Service/Institute of Food and Agricultural Sciences/University of Florida/Christine Taylor Waddill, Dean. 


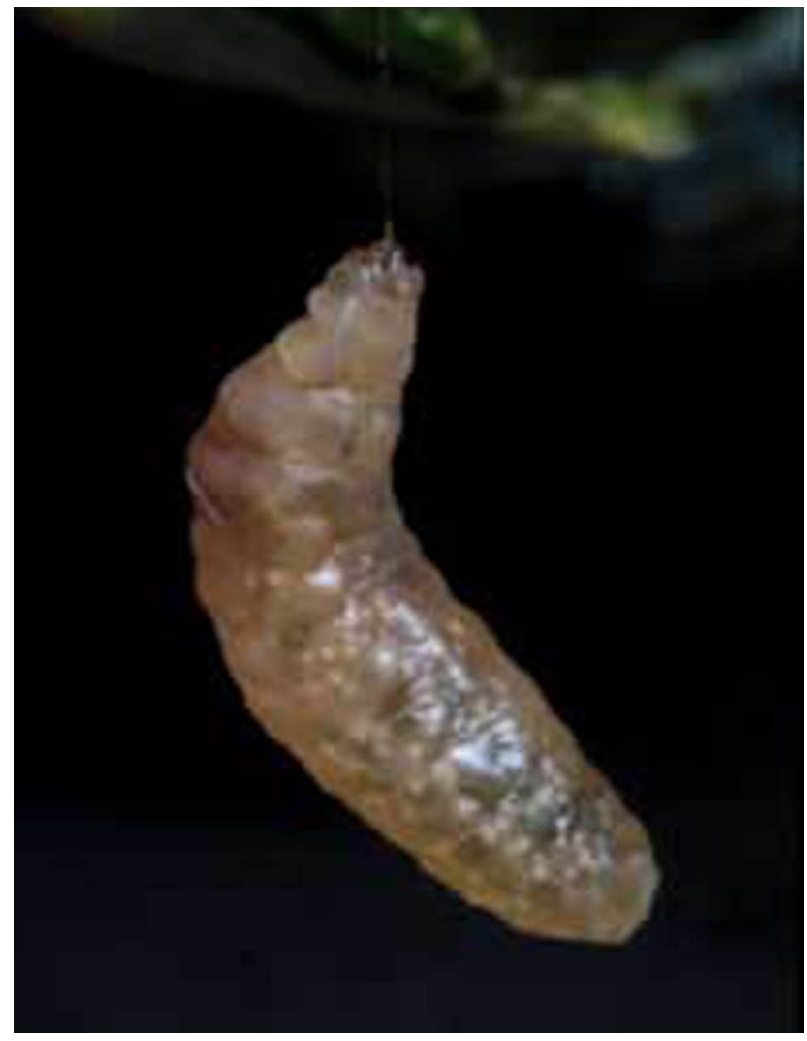

Figure 2. Pre-pupation larva of Meteorus autographae Muesebeck, a parasitoid wasp. Credits: Andrei Sourakov, USDA

During its life span in the laboratory, a female lays on average 240 eggs, though sometimes the number of progeny can reach 350 . Development from egg to pupa takes approximately eight days at 27 degrees C. It takes six more days for the adult to develop. This time triples when the temperature drops to 16 degrees C.

\section{Hosts}

The hosts for this wasp include: Acleris variana (Fern.), the eastern blackheaded budworm; Agrotis ipsilon (Hufn.), the black cutworm; Alsophila pometaria (Harr.), the fall cankerworm; Anticarsia gemmatalis Hbn., the velvetbean caterpillar; Autographa sp.; A. biloba (Steph.); Autoplusia egena (Guen.), the bean leafskeltonizer; Colias eurythema Bdvl.; Evergestis stramminalis Hbn.; Helicoverpa zea (Boddie), the bollworm (also called corn earworm and tomato fruitworm); Orgyia leucostigma (Sm.), the whitemarked tussock moth; Peridroma saucia (Hbn.), the variegated cutworm; Plathypena scabra (F.); Pseudaletia unipuncta (Haw.), the armyworm; Pseudoplusia includens (Wlkr.), the soybean looper;

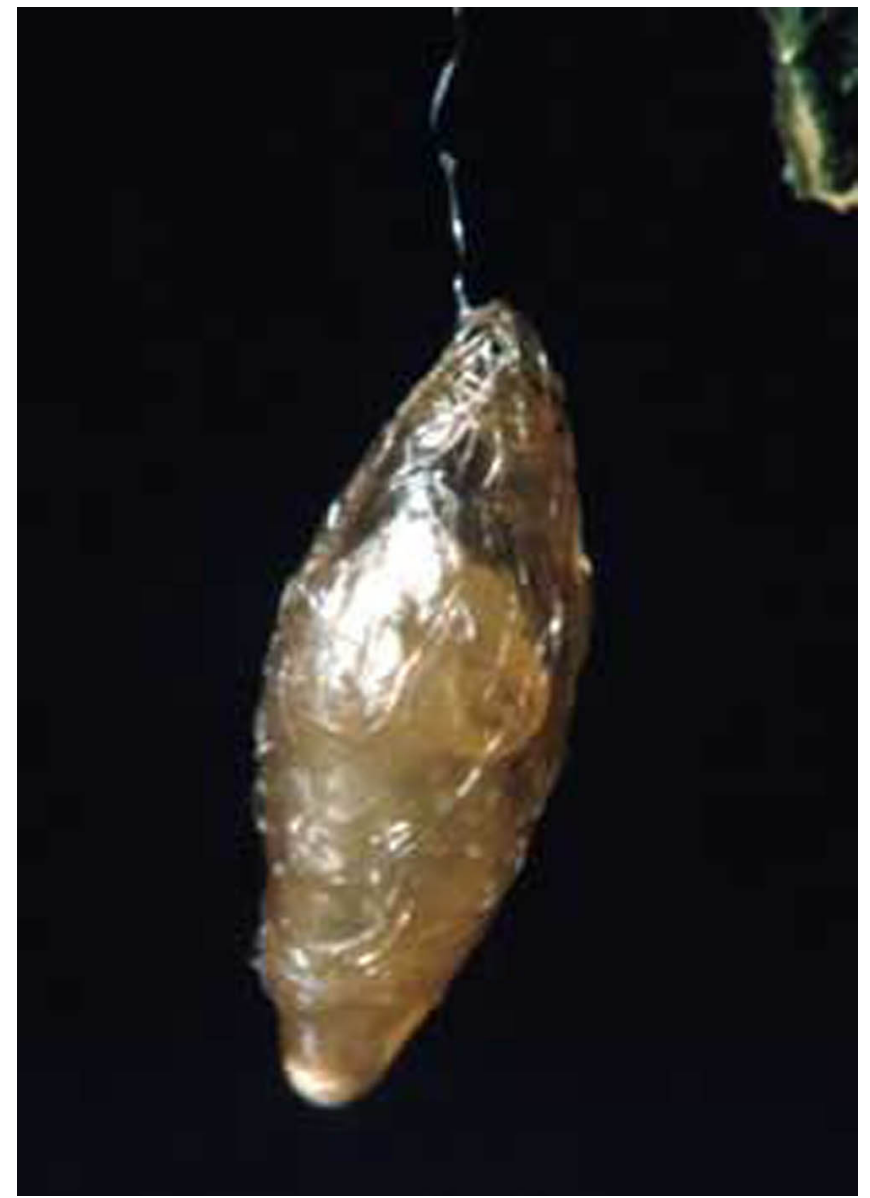

Figure 3. Cocoon of Meteorus autographae Muesebeck, a parasitoid wasp. Credits: Andrei Sourakov, USDA

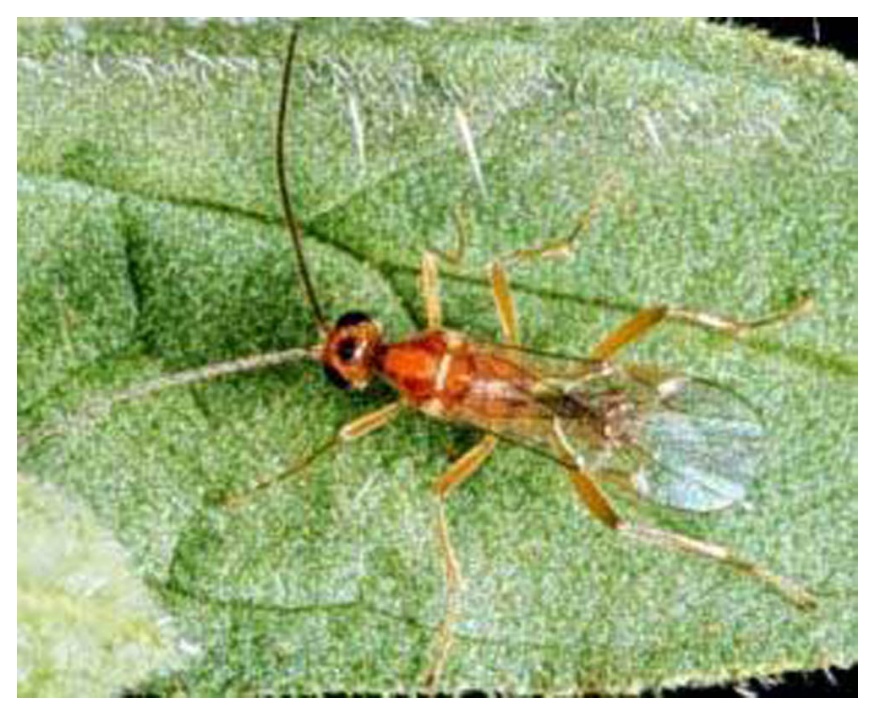

Figure 4. Male Meteorus autographae Muesebeck, a parasitoid wasp. Credits: Andrei Sourakov, USDA

Spodoptera eridania (Cram.), the southern armyworm; S. exigua (Hbn.), the beet armyworm; $S$. frugiperda (Sm.), the fall armyworm; S. ornithogalli (Guen.), the yellowstriped armyworm; Trichoplusia 


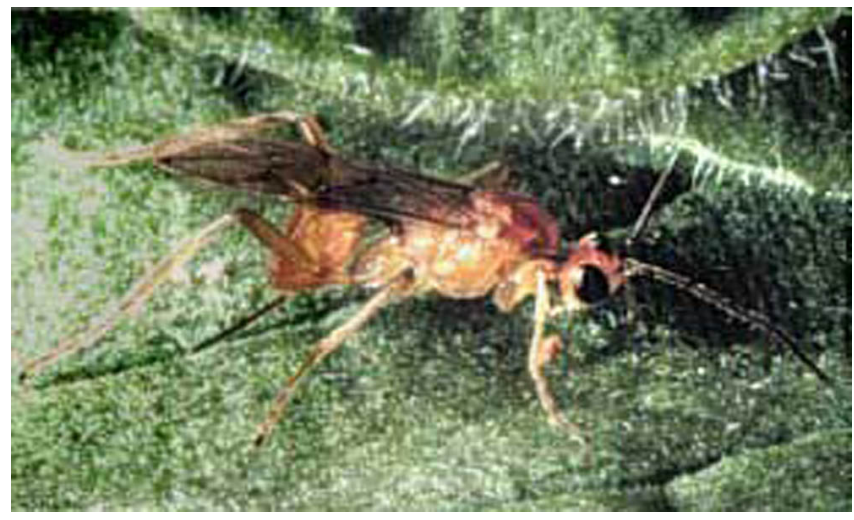

Figure 5. Female Meteorus autographae Muesebeck, a parasitoid wasp. Credits: Andrei Sourakov, USDA

$n i$ (Hbn.), the cabbage looper; and Udea rubigalis (Guen.), the celery leaftier (also called the greenhouse leaftier).

\section{Importance}

M. autographae was found to be an important control agent of soybean looper (up to $24 \%$ of this pest's larvae were found to be parasitized in South Carolina). In Florida, it was found emerging from cabbage looper larvae. Many other species of noctuids were found to be a suitable host, and, most importantly, all larval instars were parasitized. Many other cabbage looper control agents (e. g., Cotesia marginiventris) attack only young larvae, which limits their effectiveness in control of these pests.

\section{Selected References}

Grant J. F. and M. Shepard. 1984. Laboratory biology of Meteorus autographae (Hymenoptera: Braconidae), an indigenous parasitoid of soybean looper (Lepidoptera: Noctuidae) larvae. Environ. Entomol. 13: 838-842.

Grant J. F. and M. Shepard. 1986. Seasonal incidence of Meteorus autographae on soybean looper larvae on soybean in South Carolina, and the influence of the host density on parasitization. J. Entomol. Sci. 21: 338-345.

Mitchell, E. R. et al. (February 2000). Stage by stage comparison of parasitoids important in biocontrol of cabbage pests. USDA. http://www.usda.ufl.edu/biocontrol/guide.htm (March 2000). 